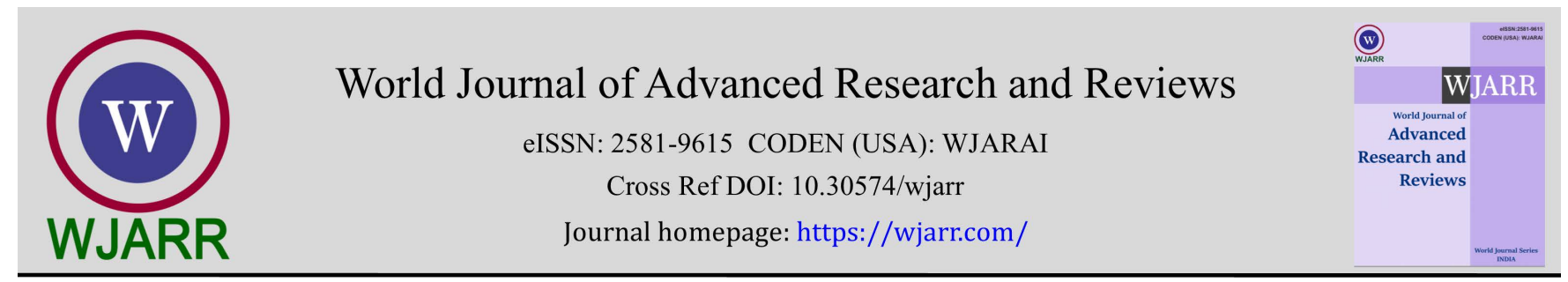

(REVIEW ARTICLE)

\title{
Ayurvedic remedies of tuberculosis
}

\author{
Jeehan Mahamed Choudhary *, Trupti Parab, Aditi Chorage, Kajal Kesharvani, Nameerah Rakhe and Kaif \\ Ahmed Shaikh
}

Department of pharmacy, Anjuman-I-Islam Kalsekar Technical Campus, Panvel, District Raigad, Maharashtra, India.

World Journal of Advanced Research and Reviews, 2021, 11(03), 280-290

Publication history: Received on 18 August 2021; revised on 19 September 2021; accepted on 21 September 2021

Article DOI: https://doi.org/10.30574/wjarr.2021.11.3.0466

\begin{abstract}
Tuberculosis is an airborne infection that impairs lung function, and people with low immunity and other medical conditions are the most vulnerable. The disease progresses slowly, with symptoms appearing only in the advanced stages, followed by a lengthy therapeutic regimen and, finally, a long list of side effects. Some patients may not complete the course or may fall behind over time. This could lead to multi-drug resistance, which would make the treatment more challenging. Ayurvedic remedies have been shown in such cases to integrate with the body's natural environment and, according to many recent studies, significantly cut mortality rates. The key reason for the growing popularity of ayurvedic medicine is the lower toxicity study and lack of side effects when partnered with allopathic medications. This review covers a brief history of the disease, its mode of action, and its symptoms, but the main focus is on ayurvedic herbs and their anti-tubercular properties. The purpose of this review is to highlight research findings on antitubercular plants and their anti-tubular action, as well as the chemical constituents of these plants.
\end{abstract}

Keywords: Anti-tubular; Vulnerable, mortality rates; Multi-drug resistance; Therapeutic regimen

\section{Introduction}

Tuberculosis known as 'the white plague' is an infectious disease caused by Mycobacterium tuberculosis. Other Mycobacterium complex responsible for Tuberculosis are Mycobacterium africanum, Mycobacterium avium complex \& Mycobacterium bovis. Tuberculosis bacteria mainly affect lungs (pulmonary Tuberculosis) but it can also attack any part of body such as Kidney, brain, etc. In Ayurveda, Tuberculosis is known as rather compared to Rajayakshma (king of diseases) /Shosha (depletion of body tissues) / Kshaya (lowered internal and external body activity), which is primarily remark of Dhatukshaya (Tissue loss or damage) [1].

In Early years of infection, tuberculosis is known as Yakshma in ayurvedic medicine, later it got a name Rajayakshma. Around 500 before the Common Era (BCE) Moon-God, the king of the Brahmanas was the first to become a victim of this disease, which is as a result known as Rajayakshma, or king's disease [2]. This disease is also called as sosha in Ayurveda due to shrivel of active or essentials of the body like Rasa - Serum etc. It is being said that when the fundamental doshas (pitta, vata, kapha) of our body performs separate functions this disease occurs.

The bacterial infection of tuberculosis intimates the process of pathogenesis/ development, there is Dhatwagninasana (metabolic dysfunction) in which rasa (tissue fluid), rakta (blood), mamsa (muscle), meda (adipose tissue), and sukra (generative tissue) are damaged severely and sometimes lost/ Cannot be recovered. This leads to ultimate becoming progressively worse of immunity or ojokshaya. According to ayurvedic concept, unusual metabolic change (Pratilomakshaya) occurs leading to loss of various dhatus (tissue). The dhatus (tissue) in the body gets desiccate and leads to feeble immune system. Due to feeble immune system the bacteria which enters the body leads to Kshayaroga.

\footnotetext{
${ }^{*}$ Corresponding author: Jeehan Mahamed Choudhary

Department of pharmacy, Anjuman-I-Islam Kalsekar Technical Campus, Panvel, District Raigad, Maharashtra, India.

Copyright (@) 2021 Author(s) retain the copyright of this article. This article is published under the terms of the Creative Commons Attribution Liscense 4.0.
} 
In Atharvaveda, involvement of ojas/ Body strength has been linked with Rajayakshma. Yakshma spreads from one person to another (Jayana), it is communicable disease. Tuberculosis spread through the air (also termed as air borne disease) when people who have active tuberculosis cough, spit, speak, or sneeze.

\subsection{Symptoms}

According to Ayurveda, symptoms of Tuberculosis/ Rajayakshama includes;

- Overexertion, getting tried easily upon doing small things

- Decreased physical urge of sneezing, urine, faeces

- Loss of body fluids, lubricant, tissues (ojas), semen

- Improper diet habits

- Swelling of Scrotum and appearance of Atisara (diarrhoea)

Because of above mentioned causes, Vata dosha gets evaluated which results in increased production of pitta and kapha, and their spread to all joints and channels which are present in body. As a result, the openings of the channels get blocked or dilated and results in disease causing the reduction in number of the body tissues.

Clinical symptoms of these diseases include;

- Nasal blockage/ congestion leading to difficulty in breathing

- Loss of appetite, desire/ feeling of hunger

- Head, shoulder or sometimes body pain, joint pain

- Vomiting sometimes accompanied with gastrointestinal track discomfort, bowel discomfort (either loose motions or constipation).

\subsection{Diagnosis}

The confirmed patients of pulmonary tuberculosis fulfilling the inclusion (included in body) and exclusion (Body surface) criteria were assessed with subjective criteria as following;

- Cough with or without fever for more than three weeks, sputum production, and debility, loss of body tissue, weakness and general condition of health.

- The objective criteria comprising of sputum Acid-fast bacillus test positive, X-ray of chest.

- Investigations including sputum bacterial load (negative patients after treatment consecutive three days on $24 \mathrm{~h}$ collected sputum).

- Immunoglobulin IgA, IgM, was estimated by agar gel prepared with human antibody IgA, IgM separately. The zone was calculated and matched with the standard scale provided by Hoechst, India.

- Total body water (TBW), fat free mass (FFM), body mass index (BMI) and total body fat (TBF) tested on selected patients of pulmonary tuberculosis and of normal matching age volunteers. Comparatively studies [3].

\section{Pathophysiology of tuberculosis}

Tuberculosis is potentially serious contagious infection usually caused by one of two forms of mycobacterium

- Mycobacterium Tuberculosis

- Mycobacterium Bovis

That mainly affects the lungs (Pulmonary tuberculosis) and also affect other body parts (Extrapulmonary tuberculosis)

Phases of pulmonary tuberculosis as follows:

- Primary tuberculosis/Ghon's complex/Childhood Tuberculosis

- Secondary tuberculosis/Reinfection/Chronic Tuberculosis 


\subsection{Primary Infection [4].}

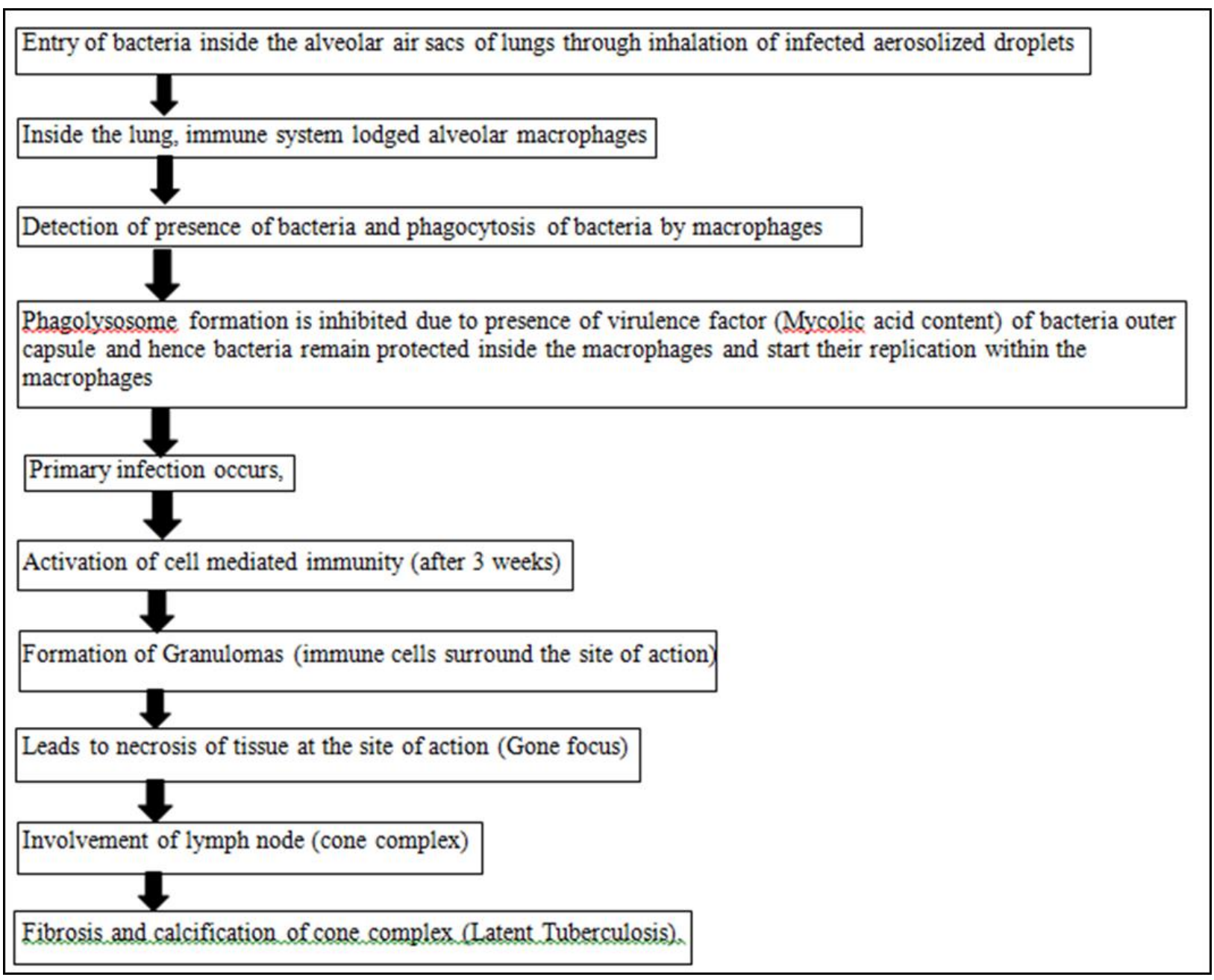

Figure1 Steps in Primary Infection

- Latent tuberculosis is asymptomatic and do not spread. Latent tuberculosis is capable of being reactivated after immunosuppression in the host

- Immune system can be compromised by immunosuppressive drugs (steroids, calcineurin inhibitors etc), Human Immunodeficiency Virus infection, malnutrition, aging, other factors etc due to which bacteria can be re-activated, multiply, move out from Granulomas and spread to other parts of lungs causing Active pulmonary tuberculosis

- This re-activation may occur even after months or some years from the initial infection, this condition is known as Secondary Tuberculosis or Reinfection

- In some cases, bacteria may also spread to any part of body including meninges, kidney, bones and lymph node via lymphatic system or blood stream

- This widespread form of Tuberculosis is known as Miliary Tuberculosis or Disseminated Tuberculosis commonly occurs in very young, very old or those with HIV infection [5]. 


\subsection{Allopathic remedies for tuberculosis: [6].}

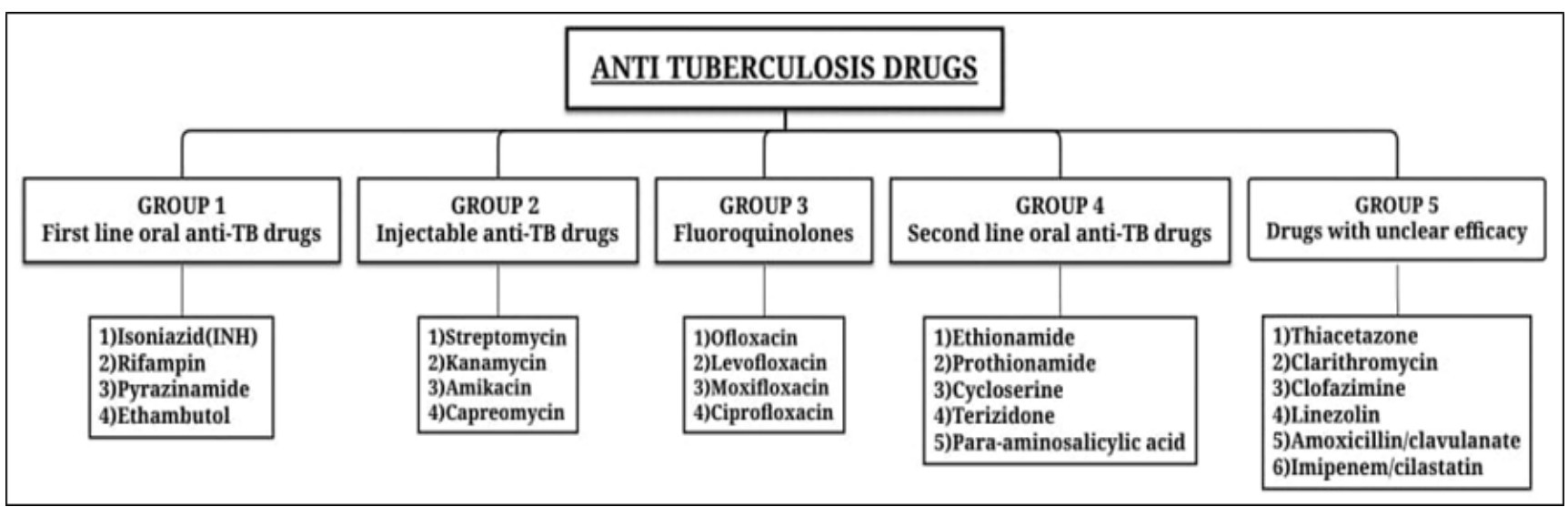

Figure 2 Classification of Anti Tuberculosis Drugs

\section{Ayurvedic remedies for tuberculosis}

\subsection{The approach of Ayurveda in the treatment of tuberculosis}

As the adverse drug reactions of allopathic medicines were harmful and highly toxic to the patient. So, researchers decided to approach the doors of the Ayurvedic system of medicine. Tuberculosis (Yakshma) named as Balasa in the Vedic literature and it's also known as Rajayakshma, Kshaya. In 1933, the establishment of Patipukur Tuberculosis Hospital, Kolkata takes place for the initial research of the ayurvedic treatment for Tuberculosis. Later on, a welldeveloped fully trained research unit was appointed with extensive financial resources. Regulatory guidelines for the treatment of Tuberculosis were adopted based on the ayurvedic principles for therapeutic management which was a significant achievement for Pre-Independence India. Medicines containing elements like mercury, gold, calcium was formulated at the in-house pharmacies and was administered to the patients with fresh juice of herbs that were extracted and cultivated in the botanical gardens. Herbal formulations like Vasantamalati, Kanchanabhra rasa, Rajamriganka rasa were used including Bhallataka (Semicarpus Anacardium - nut tree) rasayana, Vasa (Adatoda vasica - adulsa) etc. [7]

\subsection{Ayurvedic medicinal plants used to cure tuberculosis: $-[8,9,10,11]$}

\subsubsection{Adulsa (Vasaka)}

Scientific name - Justicia vasica

Common names - Malabar nut, adulsa, adhatoda, vasa, vasaka

Family - Acanthaceae

Chemical constituent- Vasicine, vasicinone, sicinolone

Medicinal Uses: It is used to treat all types of coughs, chronic bronchitis and asthma. The fruits are used to cure a cold, antispasmodic and bronchitis conditions.

\subsubsection{Ashwagandha}

Scientific name - Withania somnifera

Common names - Indian ginseng, poison gooseberry, or winter cherry

Family - Solanaceae

Chemical constituent- Withanolide, Withaferin A

Medicinal uses: It's an immunity booster herb that basically acts on the nervous and respiratory system. It has some magnificent properties to heal the wound also possesses anti-inflammatory action and rejuvenating properties. Used to cure symptoms of Tuberculosis i.e., cough, cold, bronchitis.

\subsubsection{Brahmi}

Scientific name - Bacopa monnieri

Common names - Hyssop, water hyssop, thyme-leafed gratiola, herb of grace and Indian pennywort.

Family - Plantaginaceae 
Chemical constituent - Alkaloids like brahmine, herpestine, and nicotine; saponins such as d-mannitol and hersaponin, acid $\mathrm{A}$, and monnierin

Medicinal uses: Brahmi acts on the various systems like respiratory, nervous, digestive, circulatory, and excretory. It has several therapeutic effects which include rejuvenating properties, and can be used to cure cold, cough i.e., common symptoms of.

Used in form of extract, powder or infusion/decoction form.

\subsubsection{Garlic}

Scientific name - Allium sativum

Common name - Lahsun, Lashuna

Family - Amaryllidaceae

Chemical constituent - Sulphur containing amino acids known as alliin, ajoene, diallyl polysulfides, vinyldithiins, and Sallylcysteine.

Medicinal uses: Garlic has tremendous properties to cure various conditions such as anti-oxidants, bacteriostatic, antifungal also cures digestive issues. It plays a crucial role in the treatment of some common symptoms of Tuberculosis such as reducing cough, cold, congestion, and others.

\subsubsection{Tulsi}

Scientific name - Ocimum tenuiflorum

Common name - Holy basil

Family - Lamiaceae

Chemical constituent - Tulsi essential oil consists mostly of eugenol $(\sim 70 \%) \beta$-elemene, $\beta$-caryophyllene, and germacrene, isothymusin.

Medicinal uses: Tulsi is one of the oldest herbs prescribed by Ayurveda which consist of Carminative, stomachic, antispasmodic, antiasthmatic, antirheumatic, expectorant, hepatoprotective properties.

\subsubsection{Guduchi}

Scientific name - Tinospora cordifolia

Common name - Heart-leaved moonseed, giloy

Family - Menispermaceae

Chemical constituent - Include berberine, bitter principles, including columbin, chasmanthin, palmarin and tinosporon, tinosporoside, tinosporic acid and tinosporol.

Medicinal uses: Its antibacterial properties help to cure Tuberculosis and its prominent symptoms. Used in the form of powders and extract.

\subsubsection{Alovera}

Scientific name - Aloe barbadensis

Common name - Aloe vera, Aloe, burn plant, lily of the desert, elephant's gall

Family - Liliaceae

Chemical constituent - Anthraquinone glycosides have active principles which possess anti-tubercular activity. Aloe leaves contain glucose, galactose, mannose and glacturonic acid.

Medicinal Uses: Active constituents help in anti-tubercular activity and provide relief to patient.

\subsubsection{Amla}

Scientific name - Phyllanthus emblica

Common name - Indian gooseberry also known as myrobalan, myrobalan Malacca tree, or amla from Sanskrit amalaki Family - Phyllanthaceae

Chemical constituent - Amla is rich in vitamin C (ascorbic acid) and contains various bioactive phytochemicals, of which majority are of polyphenols (ellagic acid, chebulinic acid, gallic acid, chebulagic acid, apeigenin, quercetin)

Medicinal Uses: Boost immunity and improves digestion process of patients, also possess high anti-bacterial activity. It can be used in the form of syrup and amla juices or ayurvedic chewing tablets.

\subsubsection{Black Pepper}

Scientific name - Piper nigrum

Common name - peppercorn

Family - Piperaceae 
Chemical constituent - Aristolactams, dioxoaporphines long chain isobutyl amide, lignin, longamide, pluviatilol also contain methyl pluviatilol (fargesin), asarinine, piperine etc.

Medicinal Uses: Piperine that is highly effective phytochemical present in pepper which reduces the intensity of pain and swelling. It also possesses anti-congestion property and clears the obstructed passage, aids to improve breathing by acting as bronchodilator in tuberculosis patients.

\subsubsection{Vidirakand}

Scientific name - Pueraria tuberosa

Common name - kudzu, Indian kudzu, or Nepalese kudzu, Vidarikand, Sanskrit: Bhukushmandi

Family - Fabaceae

Chemical constituent - The tuber of the plant contains $\beta$-Sitosterol, Stigmasterol, Duidzein, Puerarin and isoflavone. It also consists some pure compounds, puerarin, daidzein and tuberosi.

Medicinal Uses: Vidirakand is highly nutritious plant primarily acts on digestive, respiratory and circulatory system. It helps in gaining weight of sick patients as weight loss is a prominent symptom of Tuberculosis. It can be used in form of extract or dry powder of tubers.

\subsubsection{Mint}

Scientific name - Mentha $\times$ piperita also known as Mentha balsamea Wild

Common name - Peppermint, Pudina (Hybrid between water mint and spearmint)

Family - Lamiaceae

Chemical constituent - Peppermint leaves contain several essential oils including menthol, menthone and limonene.

Medicinal uses: Mint leaves are useful in managing gastrointestinal problems, relieving the symptoms of common cold, cough, congestion, acts as an anti-bacterial and anti-inflammatory.

Mint juice is given to Tuberculosis patients to improve their health.

\subsubsection{Noni}

Scientific name - Morinda citrifolia

Common name - Morinda, noni fruits and Indian mulberry

Family - Rubiaceae

Chemical constituent - The major chemical constituents of this plant include anthraquinones, flavonol glycosides, iridoid glycosides and triterpenoids.

Medicinal Uses: Morinda has an antimicrobial activity against tuberculosis bacteria. The Noni phytochemical present in plant can destroy the causative agent of Tuberculosis i.e., mycobacterium tuberculosis.

\subsection{General methods of extraction for herbal medicines [12]}

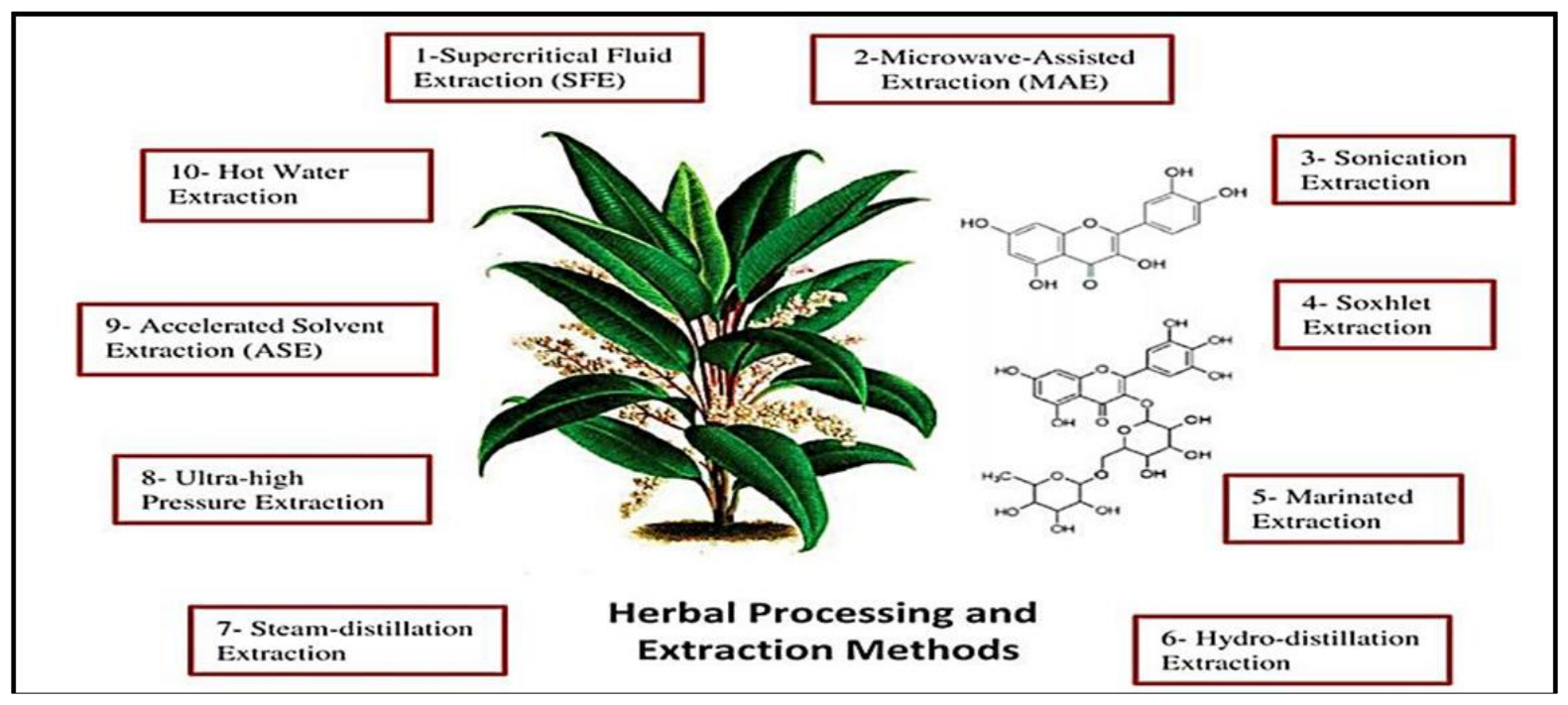

Figure 3 The 10 extraction methods described in the text 


\subsection{Ayurvedic medicines used to cure tuberculosis: - [13]}

Studies has shown that ayurvedic therapeutic preparations are highly effective to cure and relief the symptoms of tuberculosis. Ayurvedic medicines are used to cure Tuberculosis are extracted from root and tubers of plants.

Some of the highly effective herbal preparations/medicines are:

\subsubsection{Pranrakshak Churna}

This herbal preparation consist several medicinal extracts obtained from herbs like Shirish, Vaasaka, Dalchini, Cinnamon Kantkari etc which gives effective result in treatment of tuberculosis. As Praanrakshak indicates us to take care of our overall health. The churna used to cure signs and symptoms related with this

Since ages, chyawanprasha is consider disease and helps to treat Tuberculosis.

Dosage - After meals take 1-2 teaspoonful twice per day

\subsubsection{Tulsi Capsules}

It acts as immunity booster for tuberculosis patients. The natural extract of herb basil leaves is used as crucial ingredient in the preparation of capsules. Tulsi capsules maintain the balance of three doshas mentioned in ayurveda (Vaat, Pita, Kaph), the body tissues. If each dosha is properly balance in human body then tuberculosis can be easily cured by using herbal medications along with allopathic medicines.

Dosage: After meal take 2 capsules per day with warm water or as directed by physician.

\subsubsection{Chyawanprashavaleha}

as an effective immunity booster which includes several herbs like large size, fresh and ripe amla fruits, natural honey, sesame oil, myrobalan, punarnava, black pepper, basil extract etc. The extract shows significant effect in pushing the cough from body i.e., acts an expectorant lead to decongestion which relives the patient. Most effective ayurvedic preparation to treat respiratory disorder such as asthma and bronchitis.

Dosage - can be consumed on empty stomach in morning and also in evening (twice a day).

\subsubsection{Giloy Herbal Capsule}

Giloy used as antioxidant which helps to neutralize free radicals and reduce inflammation (i.e., anti-inflammatory). These capsules are $100 \%$ herbal-based formulation which is effective in to boost up the immunity, act as antifungal and antiviral, blood purifier, flushes out harmful toxin from body, also used to cure the respiratory problems such as cough, cold, breathing problems etc.

Adoptogenic properties used to improve digestive system, reduce stress, anxiety, calmness etc

Dosage form: 1-2 capsule twice a day.

\subsubsection{Kaas -Har Churna}

It is an amazing remedy to cure the cough and cold conditions. It consists of natural medicinal ingredients used for its preparation are Pippali (Piper nigerum), Ela (Eletteria cardamomum), Dalchini (Cinnamon) etc. It maintains all three doshas (Vata, Pitta, and Kapha) present in the body. Churna acts as a vasodilator which increases the blood circulation in respiratory system. Also, relief the cough by cleaning the respiratory tract. Churna boost the immunity. Using this churna we can manage the sign and symptoms of tuberculosis.

Dosage: Should be taken half an hour after meals,1-2 teaspoonful along with water twice daily.

\subsubsection{Swasani Herbal Capsule}

This capsule includes pure, standardised, natural medicinal extract that are primarily deal with all the respiratoryrelated conditions. This works efficiently in several symptoms of Tuberculosis like cold, cough, difficulty in breathing, chest pain, sinus problems, pulmonary throat infections and problems. It is quite useful in clearing the passage of respiratory tract of person so that the patient can breathe easily without any difficulty. 
The capsule is proper mixture of natural shirish, kanthkari, bharangi, anantmool, honey, cinnamon bark, basil leaves, etc, which are suggested in the Ayurveda and deals with respiratory-related disorders. The capsules act as an expectorant, antibacterial, antiseptic, purifying the lungs, and relieving cough, cold, and congestion problems.

Dosage- Before the meal take 1 capsule (twice per day).

\subsubsection{Curcumin Herbal Capsules}

Curcumin capsules are 100\% herbal-based preparations which acts as an anti-inflammatory agent, bactericidal, antiseptic, antioxidant, anti-microbial thus work significantly in the infectious condition and reduces swelling, clears the obstructed passage for easy breath, eliminates excess toxins from the body, improves the immune system by providing multiple health benefits to patient.

Other than this, the Curcumin capsule possess significant several medicinal properties, including strengthening the body's overall energy, improving digestion process, purifying blood and overall balancing the excess Kapha (kapha dosha- cough as per Ayurveda) in Tuberculosis patients.

Dosage form -Take daily 1-2 capsules twice a day as directed by physician.

\subsubsection{Bhringrajsava}

An ayurvedic preparation containing pure and authentic extract of bhringraj (bhangra plant), haritaki, pippali, twak, tejpatra, adulsa and jaggery etc. It has amazing nutritive and antibacterial properties as nutrition improves the weak immune system of patient and antibacterial property prevent further spreading of bacteria in body.

It balances the 3 dosha of human body by balancing the digestion process.

Dosage - 2-3 tablespoon daily before lunch and dinner.

\subsubsection{Eladi Churna}

Eladi churna comprises of cardamom, dalchini bark and its leaves, nagakesara (Indian rose chestnut), maricha (black pepper), pippali (long pepper) and shunthi (dried ginger). It has several immunity boosting properties like improving the digestion process, a potent carminative as well as anti-inflammatory agent. It is very much helpful in the management of congestion, cough, bronchitis, inflammation of the throat and chest, and loss of appetite.

All of these signs and symptoms are closely related with tuberculosis patients, due to which eladi churna is effective in the improving the life of Tuberculosis patients

Dosage - 20 grams is mixed in $100 \mathrm{ml}$ of Ayyappala Keratailam and applied topically over the body.

\subsubsection{Sitopadi Churna}

This churna is made from bamboo resin, cinnamon, long pepper and cardamom which are effective in Tuberculosis. It has anti-inflammatory properties which reduces the swelling, some digestive herbs for improvement of digestion, expectorant agent (to expel cough), sedative (induces sleep), anti-bacterial and properties, which help in the controlling the severe symptoms of tuberculosis.

Dosage - Usually given in 1-3 gm times a day before and after meal with honey or ghee for better therapeutic effect.

\subsection{Efficacy of ayurvedic medicine}

A clinical study is done for bhringrajasava to specify the significance and effectiveness for the treatment of tuberculosis and it's noted that this preparation has significant effect when its use as combination or adjunct therapy to DOTS therapy. It boosts up the immunity, and also defend various invading organism which can cause severe damage to patient's health. Clinical research has been shown that, the combination therapy of ayurvedic medicine alongside with DOTS treatment has shown significant improvement in Tuberculosis patient's life. So basically, we can conclude that the ayurvedic medicines doesn't harm our body so they can be easily prescribed as combination therapy with allopathic medications. 


\subsection{Adverse effects of ayurvedic herbs and medicines}

Most Ayurvedic medicines or supplements do not cause any serious side effects if taken as prescribed by a wellinformed and qualified Ayurvedic practitioner. Nevertheless, there are still ayurvedic herbals that are found to have drug interactions and toxicity issues. Patients are therefore advised to seek advice from a doctor before taking drugs to avoid any interaction. Most of these side effects include the warming effect of medicines which cause headaches and Gastrointestinal track problems like diarrhoea if consumed at a larger dosage [14].

A few of the side effects include:

\subsubsection{Ashwagandha}

Depending on the amount of dose taken, there may be variations in the side effects. In prescribed or less than prescribed amounts, Ashwagandha have no side effects and are relatively safe drugs, but large amounts can cause drowsiness, allergic reactions such as itching, swelling, fever, and redness. Other side effects include hypoglycaemia, diarrhoea, and liver damage from prolonged use.

\subsubsection{Tulsi}

Although the presence of chemical constituent Eugenol decreases hepatotoxicity, a higher dose of tulsi may be a cause of tachycardia, liver damage, etc., Moreover, tulsi is not to be prescribed during pregnancy as it may cause complications.

\subsubsection{Pranrakshak Churna}

This medication has no specific interaction with any dietary supplement or homeopathic medicine but intake in higher doses may result in diarrhoea.

\subsubsection{Chyawanprashavaleha}

Chyawanprashavaleha usually doesn't have a specific side effect, but in rare cases, it has been found to cause bloating, indigestion, and gas when consumed with milk. It can also cause tooth decay if not followed up with proper dental hygiene after consumption [15].

\subsubsection{Brahmi}

Brahmi in larger quantities cause itching and headaches as a side effect

\subsubsection{Lifestyle changes and dietary modification}

Diet and lifestyle choices are important in overcoming tuberculosis symptoms and preventing them from becoming chronic. A mild change in diet can increase the efficiency of treatment if done properly. There are several home treatments for treating Tuberculosis symptoms. These include basic immune-strengthening sources that may help in toxin elimination, cell and tissue revival, and have easy accessibility. Among the best ayurvedic home remedies are garlic, which has amazing antibacterial properties, mint, which has both anti-inflammatory and antibacterial action, Amla for its immune-boosting properties, and black pepper, which is an effective bronchodilator and helps in clearing congestion and improving breathing. Another one of the home remedies includes a moringa plant with constituents like oleic acid, glyceryl monooleate, and palmitate that have antibacterial properties.

- Water extracts from anti-tuberculosis plants are used to combat and treat symptoms. These include Aloe extract, Allium sp. extract (garlic, onion), Vasaka extract in measured quantities diluted in water.

- Add red rice to your diet plan with goat, crab meat, and seafood as protein and carbohydrate sources. Avoid the consumption of refined flour and sugar to the maximum limit.

- Pomegranate, spinach, mango, carrots, amla, tomatoes, wheat germ, nuts, and other antioxidant and vitaminrich fruits and vegetables should be included in the diet.

- Avoid fried or greasy food in your diet such as fast foods as these may lead to an increase in some symptoms associated with tuberculosis so avoiding them may help in early recovery.

- Drumstick soup and fresh bottle gourd juice are recommended for tuberculosis treatment, while brinjal, bitter gourd, black gram, ladyfinger, potatoes, mustard, curd, banana, and taro root should be avoided.

- Micro-nutrients like vitamins A, D, and E should be added to the diet as these are immune-boosting vitamins. Consume as many green leafy vegetables high in iron and vitamin B as possible, such as kale and spinach. 
- Make a plan to exercise/yoga daily. Breathing exercises may aid in the improvement of lung capacity, which is an important aspect of this condition. meditation as it is important for purifying and relaxing the mind, as well as for revitalizing the body.

- $\quad$ Try to decrease the intake of coffee (or any caffeinated product), alcohol and avoid tobacco in any way [16].

\section{Conclusion}

Tuberculosis has been a severe health issue in India, accounting for over 2,20,000 fatalities per year. Due to the highly contagious nature of M.tuberculii, resistance to allopathic medicines, and the serious side effects of allopathic medicines, there may be additional complications in the treatment and, in the worst cases, they may lead to liver damage, low immunity, and other complications. Ayurveda has given us a variety of treatments for tuberculosis which have turned out to be effective and promising. They are required to avoid such issues with efficient outcomes and to lessen symptoms without jeopardizing the individual's health. Several natural herbs and drugs have been revealed to have promising anti-tubercular action and have aided in the relief of the unpleasant symptoms of the disease while also serving as an immune booster, which may prove to have a significant impact on the world of allopathic drugs. This review makes an effort to identify key plants and drugs used in the treatment of tuberculosis, as well as their qualities and potential side effects in rare cases. It also offers the benefit of ayurvedic medicines and their efficacy in disease healing.

\section{Compliance with ethical standards}

\section{Acknowledgments}

We would Like to thank Prof. Masarrat Mukadam for continuous support and guidance in publishing this Review article.

\section{Disclosure of conflict of interest}

The authors declare that there was no conflict of interest regarding the publication of this manuscript.

\section{References}

[1] Janmejaya Samal. 13th Nov 2015. Ayurvedic management of pulmonary tuberculosis: A systematic review. viewed 29 June 2021.

[2] Annabel Kanabus. Information about Tuberculosis. viewed 01 July 2021. History of TB in India - Ancient times until end of colonial rule - TBFacts. 2020.

[3] RISA Admin. 19 April 2016. Symptoms of Tuberculosis. viewed 30th June 2018.

[4] Alila Medical Media. $\quad$ Tuberculosis $\quad$ (TB). $\quad$ viewed $29 \quad$ June 2021 https://www.alilamedicalmedia.com/media/63e4494c-bc90-4b5f-a058-dccd2756252e-progression-oftuberculosis-narrated-animation.

[5] Rotimi Adigun. 27th oct 2020. Tuberculosis. viewed 29th June 2021 https://www.statpearls.com/ArticleLibrary/viewarticle/30653.

[6] KD Tripathi. Essentials of Medical Pharmacology, 7th ed, Jaypee Brothers Medical Publishers(P)Ltd, $2013 ; 766$.

[7] P. K. Debnath, Jaydeb Chattopadhyay, Achintya Mitra, Anjan Adhikari, Mirza Samsur Alam, SK Bandopadhyay, Jayram Hazra, July-September 2012 the Approach of Ayurveda in the treatment of Tuberculosis. viewed 28 June 2021 https://www.ncbi.nlm.nih.gov/pmc/articles/PMC3487240/\#ref19.

[8] T Lakshmi, Anitha Roy, NE Kaviya. August 2020 Ayurvedic medicinal plants used to cure Tuberculosis. viewed 29 June 2021. https://www.researchgate.net/publication/344726156

[9] Dr. Laxmidutta Shukla. 28 February 2019 Ayurvedic medicinal plants used to cure Tuberculosis. viewed 30 June 2021. https://www.myupchar.com/en/disease/tuberculosis-tb/ayurveda.

[10] Editorial Team. 19 August 2020 Ayurvedic medicinal plants used to cure Tuberculosis. viewed 29 June 2021. https://ayurvedicmagazine.com/ayurvedic-medicine-for-tuberculosis/. 
[11] Vikrant Arya. June 2011 Ayurvedic medicinal plants used to cure Tuberculosis. viewed 1 July 2021 https://www.researchgate.net/profile/Vikrant-Arya/publication/267963188_A_Review_on_Anti-

Tubercular_Plants/links/5e1499b092851c8364b75146/A-Review-on-Anti-Tubercular-Plants.pdf

[12] Siti Nuurul Huda Mohammad Azmin, Zainuddin Abdul Manan, Sharifah Rafidah Wan Alwi, Lee Suan Chua, Azizul Azri Mustaffa, Nor Alafiza Yunus. 25 January 2016 General methods of extraction for herbal medicines. viewed 01July2021.

https://www.researchgate.net/profile/Siti-Nuurul-Huda-MohammadAzmin/publication/292077637/figure/fig1/AS:544918460432384@1506930093182/The-10-extractionmethods-described-in-the-text.png

[13] Dr. Vikram Chauhan. 03 September 2019. Ayurvedic medicines used to cure tuberculosis viewed 30 June 2021. https://www.alwaysayurveda.net/2019/09/treatment-of-tuberculosis-through-ayurveda.html.

[14] Lucy Burns. 18 December 2018. Side Effects of Ayurvedic Supplements. viewed 30 June 2021. https://healthfully.com/side-effects-of-ayurvedic-supplements-6581643.html.

[15] Dr. Jagdev Singh. 27 August 2014. Chyawanprash Benefits, Ingredients, Dosage \& Side Effects viewed 30 July 2021. https://www.ayurtimes.com/chyawanprash-benefits-ingredients-nutrition-facts-dosage-side-effects/.

[16] Drx. Hina Firdous. Diet Chart for Tuberculosis. viewed 30 June 2021. https://www.lybrate.com/topic/diet-fortuberculosis. 